\title{
Expression of Milk-Derived Antihypertensive Peptide in Escherichia coli
}

\author{
G. S. Lv' ${ }^{1}$, G. C. Huo, and X. Y. Fu \\ College of Food Science, \\ Northeast Agricultural University, \\ Harbin, Heilongjiang, 150030, China
}

\begin{abstract}
Many angiotensin converting enzyme inhibitory peptides (ACEIP) have been identified in recent years. Among all the literatures available thus far, almost all the ACEIP were obtained by means of enzymatic hydrolysis. However, little information was available on antihypertensive peptides obtained by DNA recombination technology. In the present paper, our aims were 1) to establish a new method to produce antihypertensive peptides (AHP), and 2) to study the expression profiles of different host strains (Escherichia coli JM109 and $\mathrm{DH} 5 \alpha$ ). To achieve these objectives, a DNA fragment encoding the published ACEIP, identified as FFVAPFPEVFGK (known as $\mathrm{CEI}_{12}$ ) was synthesized, ligated with the expression vector, $\mathrm{pQE} 16$, and transformed into $E$. coli JM109 and DH5 $\alpha$. SDS-PAGE analysis and Western-blotting detection demonstrated that the peptide $\mathrm{CEI}_{12}$ (fused with dihydrofolate reductase [DHFR]) was specifically expressed only in $E$. coli JM109 with IPTG induction. The expression profiles of the AHP $\mathrm{CEI}_{12}$ at different IPTG concentrations and different inducing times demonstrated no significant differences by SDS-PAGE analysis. The expression level of $\mathrm{CEI}_{12}$ (fused with DHFR) was about $500 \mu \mathrm{g} /$ L culture.
\end{abstract}

(Key words: angiotensin-converting enzyme, antihypertensive peptides, SDS-PAGE analysis, Westernblotting detection)

Abbreviation key: ACE = angiotensin converting en-
zyme, ACEIP = angiotensin converting enzyme inhibi-
tory peptides, AHP = antihypertensive peptides, Ni-
NTA = nickel-nitrilotriacetic acid, IPTG = isopropyl- $\beta$ -
D-thiogalactose, BAP = bioactive peptides, DHFR =
dihydrofolate reductase, CIAP = calf intestinal alkaline
phosphatase, RE = restriction enzyme, HRP = horse-
radish peroxidase.

Received September 13, 2002.
Accepted January 16, 2003.
Corresponding author: G. C. Huo; e-mail: gchuo8@hotmail.
com.
${ }^{1}$ Present address: College of Biotechnology and Sugar Engineering,
Guangxi University, Nanning, Guangxi, 530005, China.

\section{INTRODUCTION}

Milk protein has long been recognized as an excellent source of animal protein and food nutrients. Since a casein-derived angiotensin-I-converting enzyme inhibi-

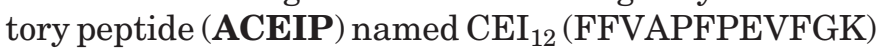
was first isolated and identified (Maruyama and Suzuki, 1982), the biological properties of milk proteins have received more attention. By far, a number of bioactive peptides (BAP), such as antihypertensive peptides (angiotensin converting enzyme inhibitory peptides) (Karaki et al., 1990; Abubakar et al., 1998; PihlantoLeppala et al., 2000), opiate peptides (Meisel, 1986; Meisel and FitzGerald, 2000), immunostimulating peptides (Kayser and Meisel, 1996; Gill et al., 2000), antithrombotic peptides (Beatrice et al., 1995), calcium-absorption enhancing peptides (Kitts and Yuan, 1992; Vegarud et al., 2000) have been identified. Among these BAP, ACEIP have received the most attention. In recent years, many ACEIP were isolated, purified, and identified from casein (Yamamoto et al., 1994; Maeno et al., 1996), whey protein (Margaret et al., 1997; PihlantoLeppala et al., 2000), cheese whey (Abubakar et al., 1998), cheese (Saito et al., 2000) and enzyme-modified cheese (Haileselassie et al., 1999), fermented milk products (Saito et al., 1994; Nakamura et al., 1995; Yamamoto et al., 1999), and other food proteins (Miyoshi et al., 1991; Yamamoto, 1997; Wu and Ding, 2001). Based on the aforementioned findings, a new criterion, more bioactive peptide fragments in the primary structure of a milk protein, for defining the nutritive value of milk proteins should be established (Wu and Ding, 2001).

Hypertension is a common disease that occurs in high frequency, and often accompanied by other diseases, including obesity, hyperlipidemia, arteriosclerosis, and coronary heart disease. The treatment of hypertension is effective in reducing the risk of such diseases. The regulation of hypertension is associated with the rennin-angiotensin system, where angiotensin converting enzyme (ACE) is considered to be the core of the system.

$\mathrm{ACE}$ (EC3.4.15.1) is a broad-range peptidyl dipeptide hydrolase that cleaves the dipeptide from the C-terminal end to the molecule. It plays a key role in the regulation of peripheral blood pressure and hypertension by catalyzing the formation of the highly potent vasocon- 
strictor octapeptide angiontensin II from the decapeptide angiotensin I, and inactivating the vasodilator bradykinin. Some ACE inhibitors, such as captopril and enarapril, have established themselves in the therapy of hypertension. As a consequence, milk-derived ACEIP, which are considered as safe and natural ACE inhibitors, can be used as potential therapeutic agents for hypertension. Fortunately, some milk-derived peptides have demonstrated potent ACE-inhibitory activities in vitro (Pihlanto-Leppala et al., 1998; Fujita et al., 2000) and blood-lowering activities in spontaneously hypertensive rats (Masuda et al., 1996; Takano, 1998), respectively. However, as mentioned above, most ACEIP were obtained by proteinase hydrolysis. No information is available on ACEIP obtained by DNA recombination technology. In the present paper, our aims were: 1) to establish a new method to produce antihypertensive peptides (AHP), and 2) to study its expression level in different host strains (E. coli JM109 and $\mathrm{DH} 5 \alpha$ ).

\section{MATERIALS AND METHODS}

\section{Biological Reagents}

BamHI, $\mathrm{T}_{4} \mathrm{DNA}$ ligase, calf intestinal alkaline phosphatase (CIAP) and PCR fragment recovery kit were purchased from Dalian Takara Co. Ltd., Dalian, China; pQE16 expression vector (a fusion expression vector with $6 \times$ His affinity tag, which can tightly bind to NickelNitrilotriacetic acid (Ni-NTA) resin and horseradish peroxidase (HRP)-labeled Ni-NTA conjugates), NiNTA agarose (Ni-NTA offers highly specific binding to $6 \times$ His-tagged protein and minimal nonspecific binding, therefore it is convenient for purification of $6 \times \mathrm{His}-$ tagged protein), HRP labeled Ni-NTA conjugates were purchased from Qiagen Co. Ltd., Valencia, CA; target gene fragment was synthesized by Dalian Takara Co. Ltd., Dalian, China (the nucleotide acid sequence was: 5' CGCGGATCCCGCTTCTTTGTGGCGCCGTTC CCGGAAGTTTTCGGCAAAGGATCCAGA $\mathbf{3}^{\prime}$ ); other chemicals were obtained from China domestic market; $E$. coli JM109 and DH5 $\alpha$ were supplied by the Genetics Department, Northeast Agricultural University, Harbin, China.

\section{Identification of Recombinants}

The target gene and expression vector were cleaved with the restriction enzyme (RE) $\mathrm{BamHI}$ at $30^{\circ} \mathrm{C}$, and the cleaved vector dephosphorylated by CIAP and recovered. The recovered vector and BamHI cleaved gene were ligated and then transformed into E. coli JM109. The colonies that grew on the ampicillin (Amp) plate (LB agar medium containing $100 \mu \mathrm{g} / \mathrm{ml}$ Amp) were se- lected to purify recombinant plasmids. The recombinant plasmids were cleaved with BamHI for identification. The suspected recombinant plasmids were sequenced to prove their correctness (plasmid sequencing was done by Unigene Co. Ltd., Shanghai, China).

\section{Expression of the Recombinant Protein}

The recombinant $E$. coli JM109 colony was inoculated into $20 \mathrm{ml}$ of LB medium containing $100 \mu \mathrm{g} / \mathrm{ml} \mathrm{Amp}$ and cultured (with shaking) at $37^{\circ} \mathrm{C}$ overnight. Then, $2 \mathrm{ml}$ overnight culture were inoculated into $20 \mathrm{ml} \mathrm{LB}$ medium containing $100 \mu \mathrm{g} / \mathrm{ml} \mathrm{Amp}$ and grown at $37^{\circ} \mathrm{C}$ with vigorous shaking (about $300 \mathrm{rpm}$ ) until the $\mathrm{OD}_{600}$ $=0.6-0.8$. To induce the expression of the target protein, isopropyl- $\beta$-D-thiogalactose (IPTG) with final concentrations of $0.2,0.4,0.6,0.8,1.0$, and $2.0 \mathrm{mM}$, were added. The expression profile of $\mathrm{AHP}^{-\mathrm{CEI}_{12}}$ at different times $(1,2,3,4,5$, and $6 \mathrm{~h})$ after IPTG induction was also studied in the group receiving $1 \mathrm{mM}$ IPTG.

\section{The Purification of Recombinant Protein}

The induced culture $(100 \mathrm{ml})$ was harvested by centrifugation $(12,000 \times g, 5 \mathrm{~min}$, Avanti 30 centrifuge, Beckman, Palo Alto, CA), and the cell pellets were resuspended and washed in $4 \mathrm{ml}$ of $0.9 \%$ saline. The suspension was collected by centrifugation and lysed with $3 \mathrm{ml}$ of lysis buffer $\left(100 \mathrm{mM} \mathrm{NaH}{ }_{2} \mathrm{PO}_{4}, 10 \mathrm{~m} M\right.$ Tris $\cdot \mathrm{Cl}$, $8 M$ Urea, $\mathrm{pH}$ 8.0). Sonication (6 times for $30 \mathrm{~s}$ each time with a 10-s interval, ultrasonic homogenizer, ColeParmer Instrument Co., Chicago, IL) was then performed and the resulting solution centrifuged $(12,000$ $\times g, 20$ min, Avanti 30 centrifuge, Beckman). The supernatant was incubated for $1 \mathrm{~h}$ in $400 \mu \mathrm{l}$ of $50 \%$ Ni-NTA agarose slurry and mixed gently by shaking (about 200 $\mathrm{rpm})$. Then the supernatant-Ni-NTA mixture was loaded into an empty column with bottom cap still attached. Removed the bottom cap and collected the flow-through, then washed with $3 \mathrm{ml}$ of wash buffer (100 $\mathrm{m} M \mathrm{NaH}_{2} \mathrm{PO}_{4}, 10 \mathrm{~m} M$ Tris $\cdot \mathrm{Cl}, 8 M$ Urea, $\mathrm{pH} 6.3$ ), followed with $300 \mu \mathrm{l}$ of elution buffer (100 $\mathrm{mM}$ $\mathrm{NaH}_{2} \mathrm{PO}_{4}, 10 \mathrm{~m} M$ Tris $\cdot \mathrm{Cl}, 8 M$ Urea, $\mathrm{pH}$ 5.9). The eluate (purified recombinant protein) was collected for SDSPAGE analysis and Western blot detection.

\section{SDS-PAGE Analysis}

To carry out the SDS-PAGE analysis, all samples (each sample contained $2 \mathrm{ml}$ of culture) were centrifuged $(12,000 \times g, 2 \mathrm{~min}$, Avanti 30 centrifuge, Beckman) and the supernatant was discarded. Then the pellets were resuspended in $200 \mu \mathrm{l} 2 \times$ SDS-PAGE sample buffer and frozen until use. 


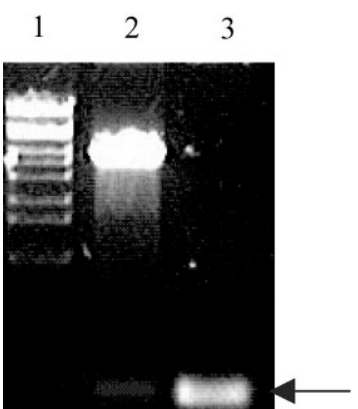

Figure 1. Identification of recombinant plasmid by Bam HI cleavage. Lane 1: DNA marker: $\lambda$ - EcoT14 I digest DNA Marker (19329bp, 7743bp, 6223bp, 4254bp, 3472bp, 2690bp, 1882bp, 1489bp, 925bp, 421bp, 74bp); Lane 2: Cleavage of recombinant plasmid by BamHI; Lane 3: Target gene shown by arrow.

SDS-PAGE analysis was performed according to the protocol described by Guo (1999). The concentration of separating and stacking gel was $15 \%$ and $5 \%$, respectively. After $2.5 \mathrm{~h}$ of electrophoresis at a constant voltage of 200V (Beijing Liuyi Apparatus Factory, Beijing, China), the gel was stained with staining solution $(1 \mathrm{~g}$ Coomassie Brilliant Blue R-250 was dissolved in a 1-L mixture of ethanol: glacial acetic acid: distilled water $=9: 1: 9$ ) for 2 to $3 \mathrm{~h}$ and then decolorized with decoloring solution (methanol: glacial acetic acid: distilled water $=1: 1: 8$ ) until the background was clear.

\section{Western Blotting Detection}

Samples were subjected to SDS-PAGE analysis described above, and the gel was then transferred to a nitrocellulose membrane (Bio-Rad electric transfer apparatus, $200 \mathrm{~mA}$ for $2 \mathrm{~h}$ ). After washing and blocking, the membrane was incubated for $1 \mathrm{~h}$ with HRP-labeled Ni-NTA conjugates (Ni-NTA can tightly bind to the $6 \times$ His-tagged protein, and therefore gives a sensitive detection of it), followed by washing, staining, and photographing (white/ultraviolet transilluminator, UVP Inc., Upland, CA).

\section{RESULTS}

\section{Identification of Recombinants}

Figure 1 shows the RE cleavage identification of recombinant plasmids extracted from positive clones of $E$. coli JM109. From the agar electrophoresis picture, it was clear that $E$. coli JM109 were successfully transformed and the target DNA fragment was cloned into the expression vector pQE16. However, we didn't know whether or not the DNA fragment was cloned in the right direction since there were two opposite directions due to single enzyme (BamHI) digestion. The sequenc-

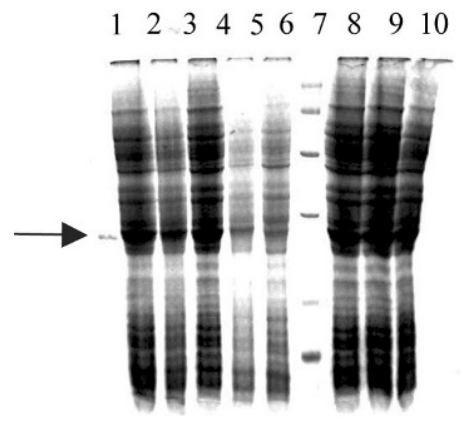

Figure 2. SDS-PAGE analysis of expression of recombinant protein induced with different IPTG concentrations. Lane 1: purified recombinant protein (fused with DHFR); lane 2, 3, 4, 8, 9, 10: induced by IPTG with final concentrations of $2,1,0.8,0.6,0.4,0.2 \mathrm{mM}$, respectively; lane 5: no n-induced sample; lane 6: E. coli JM109 (control); lane 7: standard protein marker (14.4 kDa, $20.1 \mathrm{kDa}, 31 \mathrm{kDa}$, $43 \mathrm{kDa}, 66 \mathrm{kDa}, 97 \mathrm{kDa}$ ).

ing results proved the correctness of the recombinant plasmids.

\section{Expression of the Recombinant Protein}

Figure 2 shows the expression profile of the recombinant $E$. coli JM109 at different IPTG concentrations (0.2, 0.4, 0.6, 0.8, 1.0, and $2 \mathrm{mM}$, respectively). According to SDS-PAGE, the recombinant $\mathrm{AHP} \mathrm{CEI}_{12}$ (fused with dihydrofolate reductase [DHFR]) was successfully expressed. However, no significant differences of the expression level were observed among the different IPTG concentrations studied. Figure 3 shows the expression profile of the recombinant $E$. coli JM109 at different times (1, 2, 3, 4, 5, and $6 \mathrm{~h}$ ) after $1 \mathrm{mM}$ IPTG induction. The results indicated that the recombinant AHP (fused with DHFR) was highly expressed after 3

$\begin{array}{llllllllll}1 & 2 & 3 & 4 & 5 & 6 & 7 & 8 & 9 & 10\end{array}$

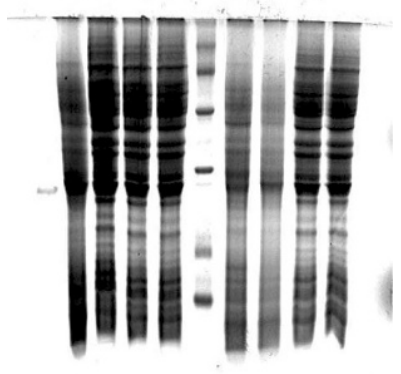

Figure 3. SDS-PAGE analysis of expression of recombinant protein at different times after $1 \mathrm{~m} M$ IPTG induction. Lane 1: purified recombinant protein (fused with DHFR); lane 2, 3, 4, 5, 9, 10: induced by $1 \mathrm{mM}$ IPTG at $1,2,3,4,5$ and 6 h, respectively; lane 7: $E$. coli JM109 (control); lane 8: no n-induced sample; lane 6: standard protein marker (14.4 kDa, $20.1 \mathrm{kDa}, 31 \mathrm{kDa}, 43 \mathrm{kDa}, 66 \mathrm{kDa}, 97 \mathrm{kDa}$ ). 


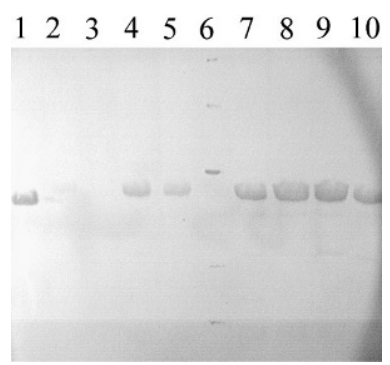

Figure 4. Western blot of recombinant protein. Lane 1: purified recombinant protein; lane 2: non-induced sample; lane 3: E. coli JM109; lane 4, 5, 7, 8, 9, 10: induced with IPTG at concentrations of $2,1,0.8,0.6,0.4,0.2 \mathrm{mM}$, respectively; lane 6: protein marker (14.4 kDa, $20.1 \mathrm{kDa}, 31 \mathrm{kDa}, 43 \mathrm{kDa}, 66 \mathrm{kDa}, 97 \mathrm{kDa})$.

$\mathrm{h}$ induction, and the highest expression level occurred at the fifth hour and decreased as time went on.

To identify whether or not the expressed protein was the desired AHP, we performed Western blotting as shown in Figure 4. The desired AHP CEI ${ }_{12}$ (fused with DHFR), which was purified by the method described above, was clearly detected.

\section{DISCUSSION}

Recently, a number of milk-derived BAP were isolated and identified. Among the BAP, ACEIP have received more research attention. The biological functions of ACEIP have been verified in vitro and in vivo, respectively (Takano, 1998). However, due to the low repeatability and production of enzymatic hydrolysis of milk proteins, no reports are available about the industrial production of ACEIP. In this study, we established a new way to produce ACEIP by DNA recombination technology. By means of DNA recombination technology, the recombinant $\mathrm{AHP} \mathrm{CEI}_{12}$ (fused with DHFR) was successfully expressed in E. coli. JM109. However, no expression was detected by SDS-PAGE analysis and Western blotting in E. coli DH5 $\alpha$ (data not shown). The possible reason may be the diverse phenotypes of different host strains.

In the study, $\mathrm{CEI}_{12}$ was expressed as a fusion protein fused with DHFR because it was unstable and easy to be degraded by the inherent enzymes of the host when expressed due to the low molecular weight of $\mathrm{CEI}_{12}$ (less than $2 \mathrm{kDa}$ ). Therefore two important problems were as follows. 1) How do we isolate and purify $\mathrm{CEI}_{12}$ from the fusion protein? Even though there is a trypsin cleavage site (Lys-X) between $\mathrm{CEI}_{12}$ and DHFR, when the recombinant protein was hydrolysed by trypsin, DHFR was also digested since there were many such sites (Lys-X and Arg-X) in it. Therefore, purification of desired $\mathrm{CEI}_{12}$ became difficult. The possible way to obtain recombinant $\mathrm{CEI}_{12}$ was the utilization of non-fusion expression vectors such as pQE60, and this work is in progress. 2) Does it have ACE inhibitory activities in vitro and blood lowering effect in vivo? These problems are being addressed through research in progress.

\section{ACKNOWLEDGMENTS}

This research was financially supported by the National Tenth-Five Economic Development Plan, National Science and Technology Ministry of China. Contract number is 2002BA901A46.

Thanks also to Professor Guicheng Huo for his careful revision of the paper.

\section{REFERENCES}

Abubakar, A., T. Saito, and K. Haruki. 1998. Structural analysis of new antihypertensive peptides derived from cheese whey protein by proteinase K digestion. J. Dairy Sci. 81:3131-3138.

Chabance, B., P. Jolles, and C. Izquierdo. 1995. Characterization of an antithrombotic peptide from $\alpha$-casein in newborn plasma after milk ingestion. Br. J. Nutr. 73:583-590.

Fujita, H., K. Yokoyama, and M. Yoshikawa. 2000. Classification and antihypertensive activity of angiotensin I-converting enzyme inhibitory peptides derived from food proteins. J. Food Sci. 65(4):564-569.

Gill, H. S., F. Doull, and K. J. Rutherfurd. 2000. Immunoregulatory peptides in bovine milk Br. J. Nutr. 84(Suppl. 1):s111-s117.

Guo, Y. J. 1999. Electrophoresis technique of protein (written in Chinese). China Publishing House of Science. Beijing, China.

Haileselassie, S. S, B. H. Lee, and B. F. Giberg. 1999. Purification and identification of potentially bioactive peptides from enzymemodified cheese. J. Dairy Sci. 82:1612-1617.

Karaki, H., K. Doi, and S. Sugano. 1990. Antihypertensive effect of tryptic hydrolysate of milk casein in spontaneously hypertensive rats. Comp. Biochem. Physiol. 96C(2):367-371.

Kayser, H., and H. Meisel. 1996. Stimulation of human peripheral blood lymphocytes by bioactive peptides derived from bovine milk proteins. FEBS Letters. 383:18-20.

Kitts, D. D., and Y. V. Yuan. 1992. Caseinophosphopeptides and calcium bioavailability. Trends Food Sci. Technol. 3:31-35.

Maeno, M., N. Yamamoto, and T. Takano. 1996. Identification of an antihypertensive peptide from casein hydrolysate produced by a proteinase from Lactobacillus Helveticus CP790. J. Dairy Sci. 79:1316-1321.

Margaret, M. M., H. Meisel, and R. J. FitzGerald. 1997. AngiotensinI-converting enzyme inhibitory activities of gastric and pancreatic proteinase digests of whey protein. Int. Dairy J. 7:299-303.

Maruyama, S., and H. Suzuki. 1982. A peptide inhibitor of angiotensin I-converting enzyme in the tryptic hydrolysate of casein. Agric. Biol. Chem. 46(5):1393-1394.

Masuda, O., Y. Nakamura, and T. Takano. 1996. Antihypertensive peptides are present in aorta after oral administration of sour milk containing these peptides to spontaneously hypertensive rats. J. Nutr. 126:3063-3068.

Meisel, H. 1986. Chemical characterization and opioid activity of an exorphin isolated from in vivo digests of casein. FEBS Letters. 196(2):223-227.

Meisel, H., and R. J. FitzGerald. 2000. Opioid peptides encrypted in intact milk protein sequences. Br. J. Nutrition. 84(Suppl. 1):s27-s31.

Miyoshi, S., H. Ishikawa, and T. Kaneko. 1991. Structures and activity of angiotensin I-converting enzyme inhibitors in an -zein hydrolysate. Agric. Biol. Chem. 55(5):1313-1318.

Nakamura, Y., O. Masuda, and T. Takano. 1996. Decrease of tissue angiotensin-I-converting enzyme activity upon feeding sour milk 
in spontaneously hypertensive rats. Biosci. Biotech. Biochem. 60(3):488-489.

Nakamura, Y., N. Yamamoto, K. Sakai. 1995. Purification and characterization of angiotensin i-converting enzyme inhibitors from sour milk. J. Dairy Sci. 78:777-783.

Pihlanto-Leppala, A., P. Koskinen, and K. Piilola. 2000. Angiotensin I-converting enzyme inhibitory properties of whey protein digests: Concentration and characterization of active peptides. J. Dairy Res. 67:53-64.

Pihlanto-Leppala, A., T. Rokka, and H. Korhonen. 1998. Angiotensin I-converting enzyme inhibitory peptides derived from bovine milk proteins. Int. Dairy J. 8:325-331.

Saito, T., T. Nakamura, and H. Kitazawa. 2000. Isolation and structural analysis of antihypertensive peptides that exist naturally in Gouda cheese. J. Dairy Sci. 83:1434-1440.

Saito, Y., K. Wanezaki(Nakamura), and A. Kawato. 1994. Structure and activity of angiotensin I converting enzyme inhibitory peptides from sake and sake lees. Biosci. Biotech. Biochem. 58(10): 1767-1771.
Takano, T. 1998. Milk derived peptides and hypertension reduction. Int. Dairy J. 8:375-381.

Vegarud, G. E., T. Langsrud, and C. Svenning. 2000. Mineral-binding milk proteins and peptides; occurrence, biochemical and technological characteristics. Br. J. Nutr. 84(Suppl. 1):s91-s98.

Wu, J. P., and X. L. Ding. 2001. Hypotensive and physiological effect of angiotensin converting enzyme inhibitory peptides derived from soy protein on spontaneously hypertensive rats. J. Agric. Food Chem. 49:501-506.

Yamamoto, N. 1997. Antihypertensive peptides derived from food proteins. Biopolymers 43:129-134.

Yamamoto, N., A. Akino, and T. Takano. 1994. Antihypertensive effect of the peptides derived from casein by an extracellular proteinase from Lactobacillus Helveticus CP790. J. Dairy Sci. 77:917-922.

Yamamoto, N., M. Maeno, and T. Takano. 1999. Purification and characterization of an antihypertensive peptide from a yogurtlike product fermented by Lactobacillus Helveticus CPN4. J. Dairy Sci. 82:1388-1393. 